\title{
Methanol Partition Fraction of Ethanol Extract of Discorea nipponica Makino Inhibits Melanogenesis
}

\author{
Hsiou-Yu Ding ${ }^{1}$, Pei-Wen Lin ${ }^{2}$, Hui-WenWang ${ }^{1}$ and Te-Sheng Chang ${ }^{{ }^{*}}$ \\ ${ }^{1}$ Institute of Cosmetics Science, Chia Nan University of Pharmacy and Science, 60, Sec. 1 Erh-Jen Rd, Jen-Te District, \\ ${ }^{2}$ Department of Biological Science and Technology, National University of Tainan, 33 Sec. 2 Su-Lin St, Tainan, Taiwan \\ *For correspondence: Email: mozyme2001@gmail.com; Tel: +886-6-2602137; Fax: +886-6-2602137.
}

\begin{abstract}
Purpose: To investigate the inhibitory effect of the methanol fraction of Dioscorea nipponica Makino ethanol extract (DNM) on melanogenesis both in vitro and in vivo.

Methods: Cultured mouse B16 melanoma cell and zebra fish were used to evaluate the melanogenesis inhibitory activity of DNM in vitro and in vivo, respectively. In B16 cells, inhibitory effects on intracellular melanogenesis, tyrosinase activity and reactive oxygen species (ROS) were determined after DNM treatment. In zebra fish, both toxic and antimelanogenic activities of DNM on developed larvae were evaluated.

Results: In B16 cells, the results show that DNM dose-dependently inhibited melanogenesis at non-toxic concentrations. Surprisingly, however, DNM had no effect on intracellular tyrosinase activity or the amount of the enzyme in B16 cells. On the other hand, DNM showed strong antioxidant activities against cell-free 2,2-diphenyl-1-picryl-hydrazl (DPPH) and 2,2'-azino-bis (3-etnylbenzthiazoline-6-sulphaonic acid) $\left(A B T S^{+}\right)$free radical and intracellular ROS in B16 cells. In zebra fish, DNM significantly and dose-dependently inhibited skin melanogenesis of zebra fish larvae at non-toxic concentrations.

Conclusion: The findings demonstrate that DNM inhibits melanogenesis in vitro in B16 melanoma cells and in vivo in zebrafish. Furthermore, DNM exhibits potent inhibition of melanogenesis probably as a result of its antioxidant activity in the cells.
\end{abstract}

Keywords: Dioscorea nipponica, Makino, Melanogenesis, Tyrosinase, Antioxidant, Melanoma, Zebra fish

Tropical Journal of Pharmaceutical Research is indexed by Science Citation Index (SciSearch), Scopus, International Pharmaceutical Abstract, Chemical Abstracts, Embase, Index Copernicus, EBSCO, African Index Medicus, JournalSeek, Journal Citation Reports/Science Edition, Directory of Open Access Journals (DOAJ), African Journal Online, Bioline International, Open-J-Gate and Pharmacy Abstracts

\section{INTRODUCTION}

The skin color of animals and humans is determined mainly by the content of melanin pigment. Melanin is produced in dermal melanocytes by a process termed melanogenesis [1], which is initiated in special organelles within melanocytes, the melanosomes. In the melanogenesis pathway, tyrosinase is the rate-limiting enzyme, which catalyzes oxidation of L-tyrosine and L-3,4-dihydroxyphenylalanine (L-DOPA) to dopaquinone. The resulting dopaquinone then forms melanin. Although melanin primarily serves a photoprotective function, over-production and accumulation of melanin result in several skin disorders including freckles, melasma, age spots, and other hyper-pigmentation syndromes. Thus several studies on the treatment of skin disorders have focused on inhibiting melanogenesis and preventing abnormal pigmentation [2-4].

Dioscorea nipponica Makino is a medicinal plant traditionally used to treat asthma, rheumatoid 


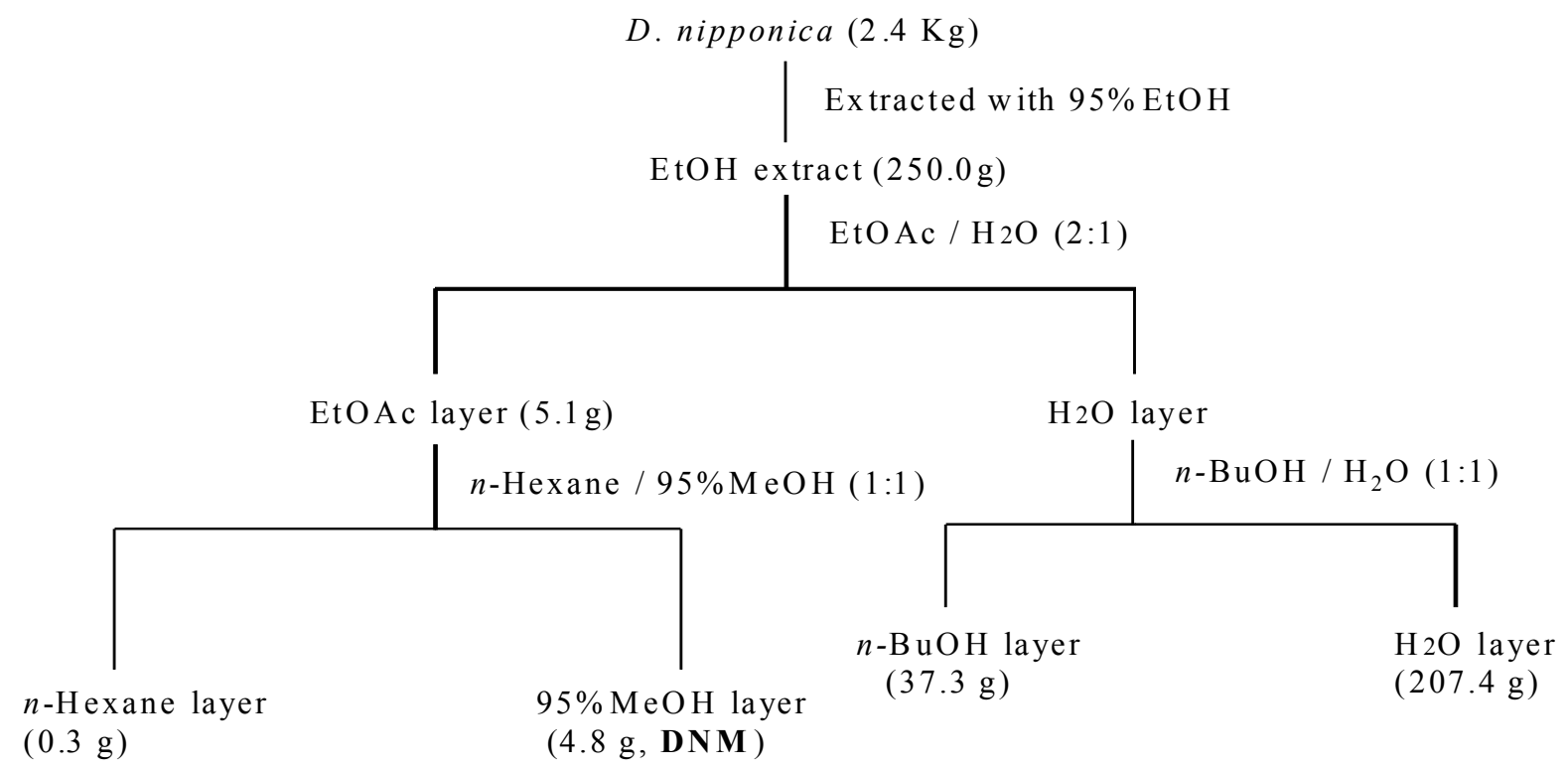

Figure 1: Scheme for preparation of DNM from D. nipponica

arthritis, bronchitis, and other diseases in Asia. D. nipponica cultures and extracts processed in health care have been produced on a large scale. For instance, the extract of $D$. nipponica is used to prepare Di-Ao Xin-Xue-Kang capsule, a botanical medicine popular in China for preventing and treating coronary heart disease [5]. The tuber of the plant is rich in dioscin, which is one of the most important pharmaceutical raw materials for synthesis of $D$. nipponica diosgenin in industry. Diosgenin is an ideal parental drug for synthesizing various variety steroidal hormones and steroidal contraceptives. Thus, investigating $D$. nipponica is becoming popular. Many studies involving $D$. nipponica have demonstrated its biological activity, including inhibition of pancreatic lipase [6], antioxidant activity [7], antitumor activity [8], and reduction of metastasis of melanoma in vitro and in vivo $[9,10]$. However, no studies have been carried out on the anti-melanogenic activity of this medicinal plant.

The aim of this study was to investigate the inhibitory effects of methanol layer of $D$. nipponica ethanolic extract (DNM) on cellular melanogenesis and tyrosinase activity in vitro in B16 melanoma cells, as well as antioxidant activities. In addition, the in vivo antimelanogenesis activity of DNM was also evaluated in zebrafish.

\section{EXPERIMENTAL}

\section{Chemicals}

3-(4,5-Dimethylthiazol-2-yl)-2,5-

diphenyltetrazolium bromide (MTT), Triton X-100, phenylmethylsulfonyl fluoride (PMSF), L-DOPA, dimethyl sulfoxide (DMSO), trypsin/EDTA, and 3isobutyl-1-methylxanthin (IBMX) were purchased from Sigma (St. Louis, MO). All other chemicals were obtained from Tokyo Chemical Industry (Tokyo) and were of analytic reagent grade.

\section{Extraction and partition of $D$. nipponica Makino}

"Chuanshanlong", D. nipponica Makino, obtained from Kwong-Te Co., Kaohsiung, Taiwan was identified by Professor HC Lin of the National Defense Medicinal Center, where a voucher specimen was deposited (CNUPS No.990824). The process for preparing DNM is shown in Figure 1. The dried powder of the bark $(2.4 \mathrm{~kg})$ was extracted 4 times with $95 \%(\mathrm{v} / \mathrm{v})$ ethanol at room temperature overnight and filtered. After the solvent was removed by a rotary evaporator (Rotavapor RII, Buchi, Switzerland), the residue $(0.25 \mathrm{~kg})$ was partitioned in $1: 2(\mathrm{v} / \mathrm{v})$ mixture of water and ethyl acetate. The ethyl acetate fraction was collected separately. The solvent in the ethyl acetate layer was removed in a rotary evaporator, and the residue partitioned in 1:1 (v:v) mixture of $95 \%$ methanol and n-hexane. To obtain DNM, the $95 \%$ methanol layer was collected and concentrated in a rotary evaporator. A yield of $4.8 \mathrm{~g}$ of DNM was obtained.

\section{Cell cultures and drug treatment}

Mouse B16 melanoma cells (4A5) were obtained from the Bioresources Collection and Research Center (BCRC, Food Industry Research and Development Institute, Hsinchu). The cells were 
cultured in Dulbecco's modified Eagle's medium (DMEM) supplemented with $10 \% \mathrm{v} / \mathrm{v}$ fetal bovine serum at $37{ }^{\circ} \mathrm{C}$ in a humidified, $\mathrm{CO}_{2}$-controlled $(5 \%)$ incubator. The cells were seeded at an appropriate cell density in a 24-well or a 6-well plate. For evaluation of the inhibitory effect of DNM on melanogenesis of B16 cells, IBMX, an agent that stimulates intracellular CAMP levels, was used to stimulate melanogenesis in B16 cells followed by DNM treatment. After $24 \mathrm{~h}$ of incubation, the cells were treated with various concentrations of drugs in the absence or presence of a stimulation agent $(100 \mu \mathrm{M}$ of IBMX) for another $48 \mathrm{~h}$. Thereafter, the cells were harvested and used for the various assays.

\section{Measurement of cell viability}

MTT assay was performed to determine cell viability. After the cells were incubated with the drugs for $48 \mathrm{~h}$, the culture medium was removed and replaced with $1 \mathrm{mg} / \mathrm{mL}$ MTT in phosphatebuffered saline (PBS) for a further $3 \mathrm{~h}$ of incubation. The MTT solution was then removed, DMSO was added, and the absorbance of the dissolved formazan crystals was determined at $570 \mathrm{~nm}$ by a spectrophotometer (U-5100, Hitachi, Japan).

\section{Determination of melanin content}

At the end of the cell culture, the cells were harvested and washed twice with PBS. The pelleted cells were lysed in cold lysis buffer (20 $\mathrm{mM}$ sodium phosphate $(\mathrm{pH} 6.8), 1 \%$ Triton $\mathrm{X}$ 100, $1 \mathrm{mM}$ PMSF, $1 \mathrm{mM}$ EDTA). After centrifugation at $15,000 \times \mathrm{g}$ for $15 \mathrm{~min}$, the melanin pellets were dissolved in $1 \mathrm{~N} \mathrm{NaOH}$ containing $20 \%$ DMSO for $1 \mathrm{~h}$ at $95{ }^{\circ} \mathrm{C}$. The melanin content was measured absorbance at $490 \mathrm{~nm}$ by a spectrophotometer (U-5100, Hitachi, Japan). The melanin content was expressed as percentage of control.

\section{Measurements of cellular tyrosinase activity}

Tyrosinase activity in B16 cells was assayed by measuring the rate of oxidation of L-DOPA. The drug-treated cells were washed with ice-cold PBS and lysed with $20 \mathrm{mM}$ phosphate buffer $(\mathrm{pH}$ 6.8) containing $1 \%$ Triton $X-100$ and $1 \mathrm{mM}$ PMSF. Triton $X-100(1 \%)$ was used to release the membrane-bound tyrosinase from the melanosomes. The cells were then disrupted by freezing and thawing. The lysates were centrifuged at $15,000 \times \mathrm{g}$ for $15 \mathrm{~min}$. The protein content in the supernatant was determined with the Bradford assay [11], with BSA as the protein standard. For assay of tyrosinase activity $1 \mathrm{~mL}$ of the reaction mixture contained $50 \mathrm{mM}$ of phosphate buffer ( $\mathrm{pH} 6.8$ ), $2.5 \mathrm{mM}$ of L-DOPA, and $500 \mu \mathrm{g}$ of the supernatant protein. After a 15 min reaction at $37^{\circ} \mathrm{C}$, dopachrome formation was monitored by measuring absorbance at 475 $\mathrm{nm}$ with a spectrophotometer (U-5100, Hitachi, Japan). The tyrosinase activity was expressed as percentage of IBMX-stimulated control.

\section{Tyrosinase zymography}

L-DOPA staining assay was performed as previously reported [12]. The cells were washed 3 times in ice-cold PBS, and lysed in cold lysis buffer ( $20 \mathrm{mM}$ sodium phosphate $(\mathrm{pH} 6.8), 1 \%$ Triton X-100, $1 \mathrm{mM}$ PMSF) containing a protease inhibitor cocktail (Abcam, Cambridge). After centrifugation at $15,000 \times \mathrm{g}$ for $15 \mathrm{~min}$, the protein content in the supernatant was determined by Bradford assay. The protein (100 $\mu \mathrm{g}$ ) was mixed with sampling buffer (no $\beta$ mercaptoethanol or heating) and separated using $10 \%$ sodium dodecyl sulfate (SDS) polyacrylamide gel electrophoresis. Gel portion containing tyrosinase activity was rinsed in 200 $\mathrm{mL}$ of $100 \mathrm{mM}$ sodium phosphate buffer $(\mathrm{pH} 6.8)$ and equilibrated at room temperature with gentle shaking. After $30 \mathrm{~min}$, the rinse buffer was replaced with fresh buffer. After the rinse procedure was repeated, the gel was transferred into $200 \mathrm{~mL}$ of a staining solution containing the rinse buffer supplemented with $2.5 \mathrm{mM}$ L-DOPA, and incubated in the dark at $37{ }^{\circ} \mathrm{C}$ for $1 \mathrm{~h}$. Tyrosinase activity was visualized in the gel as a dark melanin-containing band. The signal intensity of each band was quantified with a densitometer system GS-700 (Bio-Rad, Hercules, CA) equipped with an integrator.

\section{Determination of DPPH scavenging activity}

The assay was carried out as previously described [13] with minor modification. The DNM was added to the DPPH (1 mM) solution to a final volume of $1 \mathrm{~mL}$. After $30 \mathrm{~min}$ of reaction, the absorbance of the reaction mixture was read at $517 \mathrm{~nm}$ with a UV-VIS spectrophotometer (U5100, Hitachi, Japan). Vitamin C and Trolox were used as positive antioxidant standards. Both standards were dissolved in DMSO (1 $\mathrm{mg} / \mathrm{ml}$ ) and added to the DPPH solution for assaying.

\section{Determination of $\mathrm{ABTS}^{+}$scavenging activity}

The 2,2'-azino-bis(3-ethylbenzothiazoline-6sulphonic acid) (ABTS) assays were carried out as previously described [13] with a slight modification. The ABTS radical cation $\left(\right.$ ABTS $^{+}$) was produced by reacting $7 \mathrm{mM}$ stock solution of 
ABTS with $2.45 \mathrm{mM}$ potassium persulfate and allowing the mixture to stand in the dark for at least $6 \mathrm{~h}$ before use. For the $\mathrm{ABTS}^{+}$scavenging activity, the DNM was added to the $\mathrm{ABTS}^{+}$ solution to a final volume of $1 \mathrm{~mL}$. After $6 \mathrm{~min}$ of reaction, the absorbance of the reaction mixture was read at $734 \mathrm{~nm}$ using a UV-VIS spectrophotometer. Vitamin $\mathrm{C}$ and Trolox were used as positive antioxidant standards. Both standards were dissolved in DMSO $(1 \mathrm{mg} / \mathrm{ml})$ and added to the ABTS solution for assaying.

\section{Determination of intracellular ROS level}

The B16 cells were cultured in 96-well plates and treated with various concentrations of DNM or positive standards (vitamin $\mathrm{C}$ and Trolox) for 2 or $24 \mathrm{~h}$. The cells were washed with PBS, and 10 $\mu \mathrm{M}$ of DCFH-DA in PBS was added to the cells for $30 \mathrm{~min}$. After incubation, the cells were then incubated with $100 \mu \mathrm{M} \mathrm{H}_{2} \mathrm{O}_{2}$ at $37^{\circ} \mathrm{C}$ for $30 \mathrm{~min}$. The fluorescence intensities of DCF were measured at an excitation wavelength of $504 \mathrm{~nm}$ and an emission wavelength of $524 \mathrm{~nm}$ using a fluorescent reader (BioTech, Synergy2).

\section{Determination of melanogenesis inhibitory activity in zebrafish}

Evaluation of melanogenesis inhibitory activity in a zebrafish model system was done according to the procedure of Choi et al [14] as modified by Lin [15]. Adult zebrafish were obtained from a commercial dealer and kept in acrylic tanks with a $14 \mathrm{~h} / 10 \mathrm{~h}$ light/dark cycle at $28{ }^{\circ} \mathrm{C}$. Synchronized embryos were obtained from natural spawning induced in the morning by turning on the light. DNM were dissolved in $0.1 \%$ DMSO and then added to the embryo medium from 9 to 72 hpf (hours post-fertilization). Fifteen synchronized embryos were included in each assay, and three independent assays were conducted for each drug concentration. The number of successfully developed zebra fish larvae was recorded at the end of the drug treatment to calculate embryo survival. Six successful developed larvae in each drug concentration were randomly selected and photographed with a digital camera under a stereomicroscope. Melanin content on the skin of the zebra fish larvae was quantified using Software Image J, which marked the entire body area and the melanin area for each larva. The melanin content was expressed as the percentage of the melanin area in the total body area.

\section{Statistical analysis}

All data in the present study are expressed as mean $\pm S D$ (at least $n=3$ ). Statistical analysis was performed using Student $t$ test. A value of $p$ $<0.05\left(^{*}\right)$ or $p<0.001\left(^{* *}\right)$ was considered statistically significant.

\section{RESULTS}

\section{Effect of DNM on cellular melanogenesis of B16 cells}

The result of cytotoxicity of DNM on B16 melanoma cells is shown in Figure 2A. It was found that DNM at a concentration of $12.5 \mu \mathrm{g} / \mathrm{ml}$ had no significant cytotoxic effect on the cells and $12.5 \mu \mathrm{g} / \mathrm{ml}$ of DNM was used as the maximal concentration for the antimelanogenic assay. Figure 2B shows the result of the antimelanogenic assay. DNM treatment as low as $3.125 \mu \mathrm{g} / \mathrm{ml}$ resulted in significant reduction $(78.4 \%)$ of melanin content induced by IBMX in the B16 cells. The inhibition of melanogenesis by
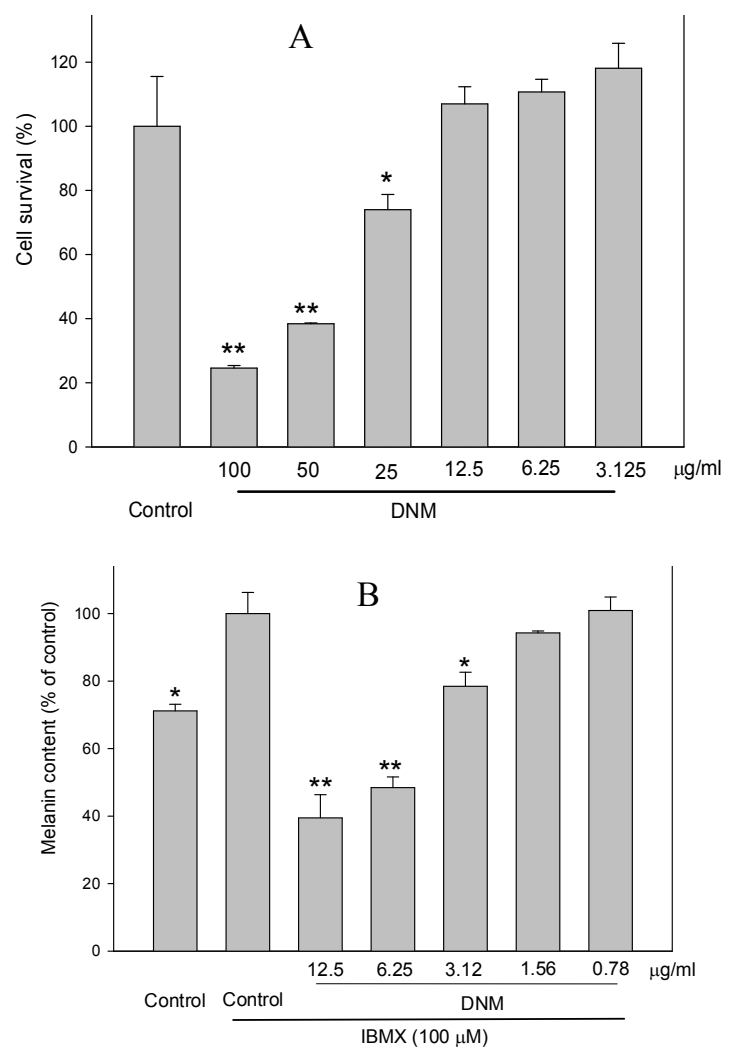

Figure 2: Effect of DNM on cellular melanogenesis in $B 16$ cells. The cells were cultivated for $1 d$ and then stimulated with $100 \mu \mathrm{M}$ of IBMX for 2-d with various concentrations of DNM; (A) Cell survival was determined by MTT method and (B) melanin content of the cells was determined by a spectrophotometer. Data are mean $\pm S D(n=3)$; error bars denote standard deviation (SD); $\left.\mathrm{p}<0.05\left(^{*}\right) ; \mathrm{p}<0.001{ }^{* *}\right)$ relative to IBMX-stimulated control. 
DNM was dose-dependent. In addition, the melanin content of the treatment by 12.5 $\mu \mathrm{g} / \mathrm{ml}$ of DNM (39.5\%) was much lower than that in the non-ibmx-stimulated cells $(71.0 \%)$.

\section{Effect of DNM on intracellular tyrosinase activity of B16 cells}

The DNM did not reduce the tyrosinase activity of the treated-cells in all tested DNM concentrations (Figure 3A). To confirm that DNM did not reduce the intracellular tyrosinase activity in advance, we conducted a tyrosinase zymographic assay, where active intracellular tyrosinase was separated on an SDS-PAGE and then stained ingel with L-DOPA. The results are shown in Figure $3 \mathrm{~B}$ and $3 \mathrm{C}$. Consistently, the amount of active intracellular tyrosinase was not reduced by DNM treatment in all tested DNM concentrations.
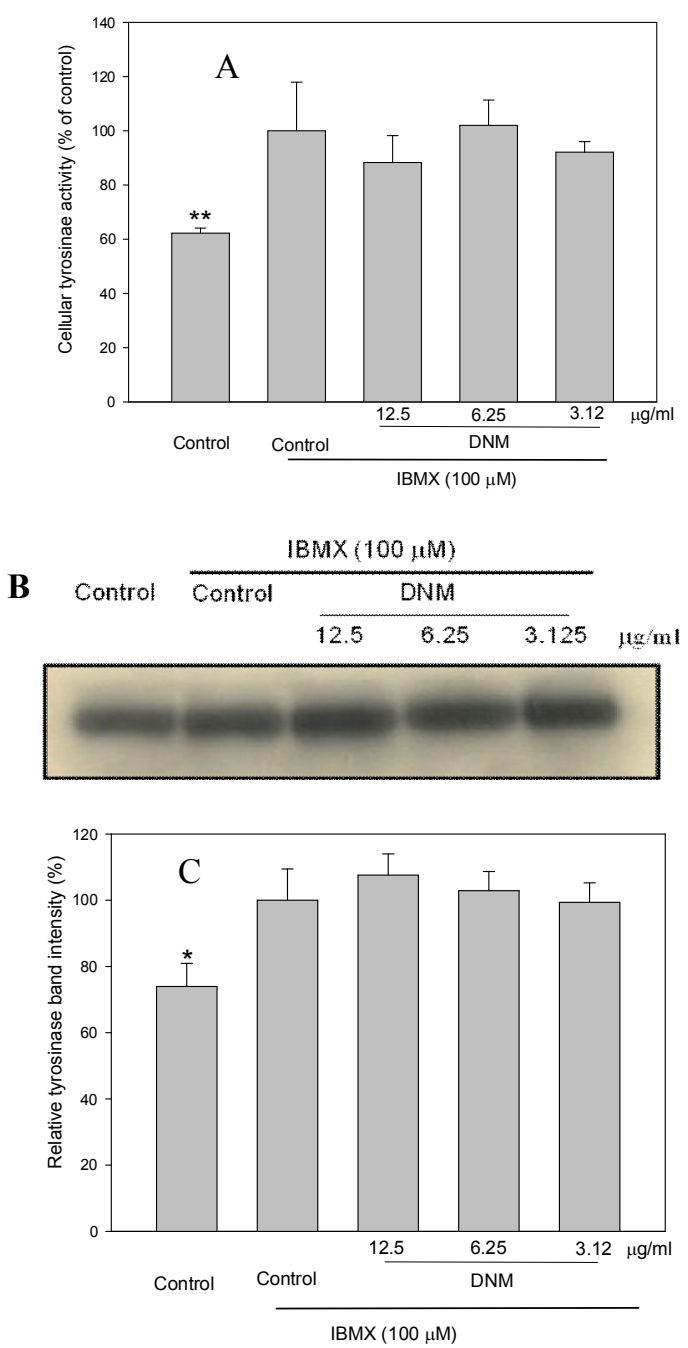

Figure 3: Effect of DNM on cellular tyrosinase activity in B16 cells (A) and on tyrosinase zymography $(B)$. Data $(A)$ are mean $\pm S D(n=3)$; error bars denote standard deviation (SD); $p<0.05$ $\left(^{*}\right) ; p<0.001\left(^{* *}\right)$ relative to IBMX-stimulated control

\section{Antioxidant capacity of DNM}

The results for antioxidant capacity of DNM are shown in Figure 4. DNM exhibited potent DPPH scavenging activity (Figure $4 \mathrm{~A}$ ) with an $\mathrm{IC}_{50}$ value of $3.12 \mu \mathrm{g} / \mathrm{ml}$, which is comparable with those of vitamin $\mathrm{C}\left(\mathrm{IC}_{50}=2.10 \mu \mathrm{g} / \mathrm{ml}\right)$ and Trolox $\left(\mathrm{IC}_{50}=\right.$ $2.11 \mu \mathrm{g} / \mathrm{ml})$. In addition, DNM also exhibited potent $\mathrm{ABTS}^{+}$scavenging activity (Figure 4B) with an $\mathrm{IC}_{50}$ value of $3.04 \mu \mathrm{g} / \mathrm{ml}$, which is comparable with those of vitamin $\mathrm{C}\left(\mathrm{IC}_{50}=1.71\right.$ $\mu \mathrm{g} / \mathrm{ml})$ and Trolox $\left(\mathrm{IC}_{50}=2.88 \mu \mathrm{g} / \mathrm{ml}\right)$. Moreover, DNM significantly reduced intracellular ROS in B16 cells with $\mathrm{IC}_{50}$ values of $14.1 \mu \mathrm{g} / \mathrm{ml}$ for $2 \mathrm{~h}$ treatment and $15.5 \mu \mathrm{g} / \mathrm{ml}$ for $24 \mathrm{~h}$-treatment. DNM exhibited much higher intracellular ROS scavenging activity than the vitamin $\mathrm{C}$ and Trolox (Figure 4C and D).

\section{Evaluation of the in vivo melanogenesis inhibitory activity of DNM}

The result of cytotoxicity of DNM against zebrafish is shown in Figure 5A. $100 \mu \mathrm{g} / \mathrm{ml}$ DNM exhibited slight toxicity to the zebrafish embryo. In addition, some embryos with $50 \mu \mathrm{g} / \mathrm{ml}$ DNM treatment showed $12-24 \mathrm{~h}$ delay in embryo development (data not shown). Therefore, we used $25 \mu \mathrm{g} / \mathrm{ml}$ as a maximal concentration to determine the inhibitory activity of DNM on melanogenesis of zebrafish. The results are showed in Figure $5 \mathrm{~B}$ and $5 \mathrm{C}$. Treatment of embryos with $25 \mu \mathrm{g} / \mathrm{ml}$ of DNM significantly reduced the skin melanin content in the developed larvae. In addition, the reduction in the skin melanin by DNM treatment was dosedependent.

\section{DISCUSSION}

For obvious reasons, during assaying of prospective bioactive compounds for modulating skin pigmentation, it is important to consider possible adverse effects on melanocyte proliferation and/or survival. Artificial antimelanogenic activity of a drug is obtained by conducting the anti-melanogenic assay under the cytotoxic concentrations of the drug. Therefore, before the effect of DNM on melanogenesis of mouse B16 melanoma cells is investigated, the concentration range of DNM, which is non-toxic to the cells, should be determined. From the results of both MTT cytotoxicity and antimelanogenesis assays, it is obvious that DNM exhibited potent anti-melanogenesis activity in vitro in B16 cells at non-cytotoxic concentrations. 


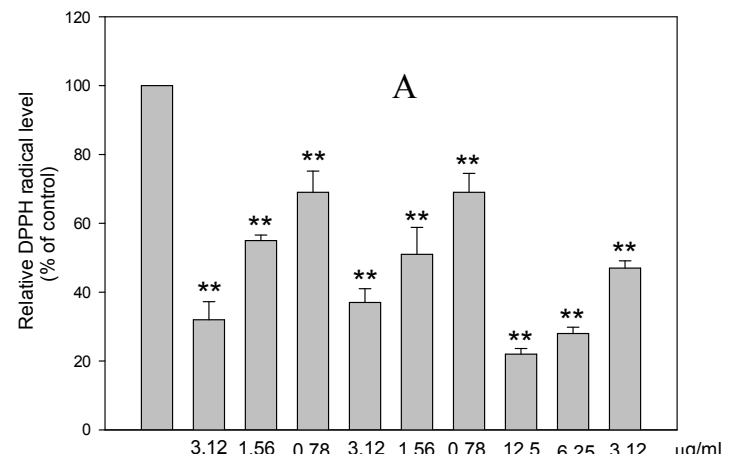

(B)

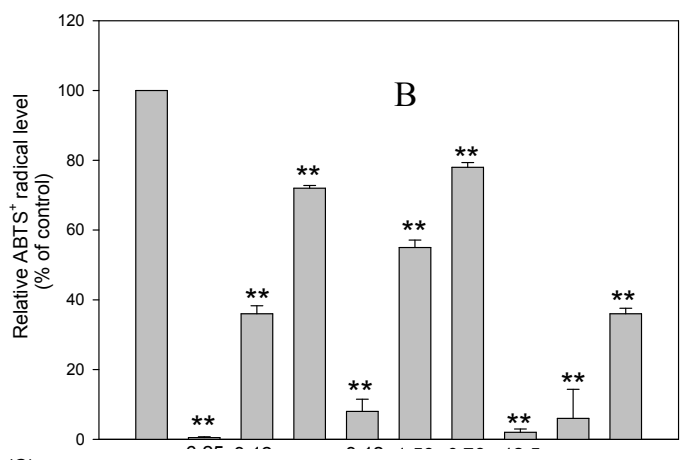

(C)

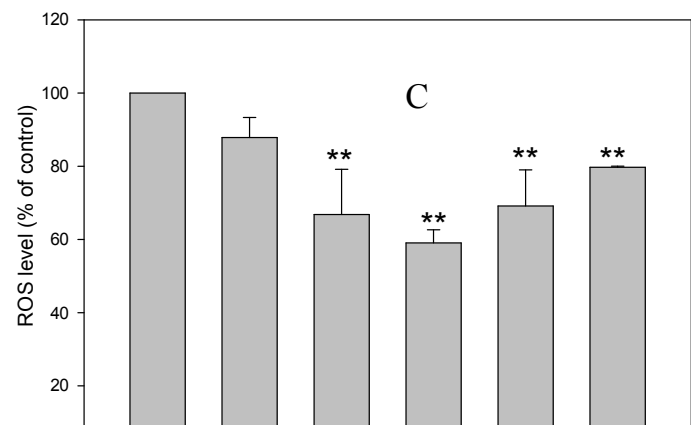

(D)

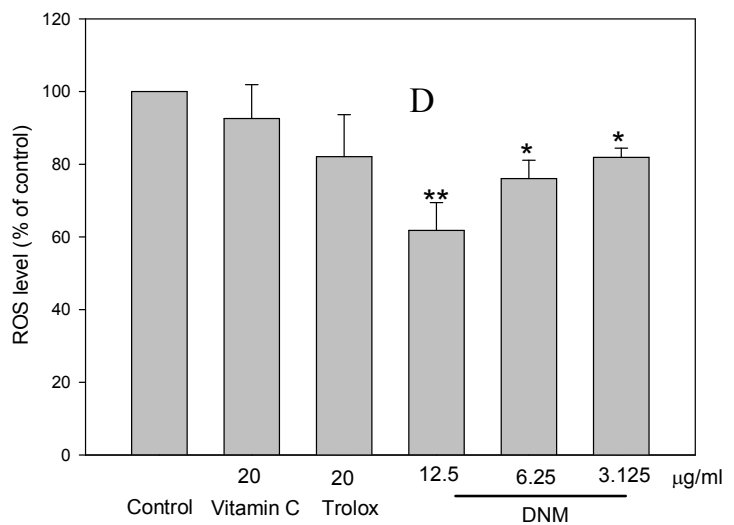

Figure 4: Antioxidant activities of DNM. (A) DPPH free radical scavenging capacity of DNM. (B) ABTS+ free radical scavenging capacity of DNM. (C) Effect of DNM on intracellular ROS level of B16 cells for 2 h-treatments. (D) Effect of DNM on intracellular ROS level of B16 cells for $24 \mathrm{~h}$-treatments. Averaged data $(n=3)$ are presented with error bars indicating SD. A value of $p<0.05\left({ }^{*}\right)$ or $p<0.001\left(^{* *}\right)$, obtained with a Student $t$-test by comparing the data with those for the control, was considered statistically significant.

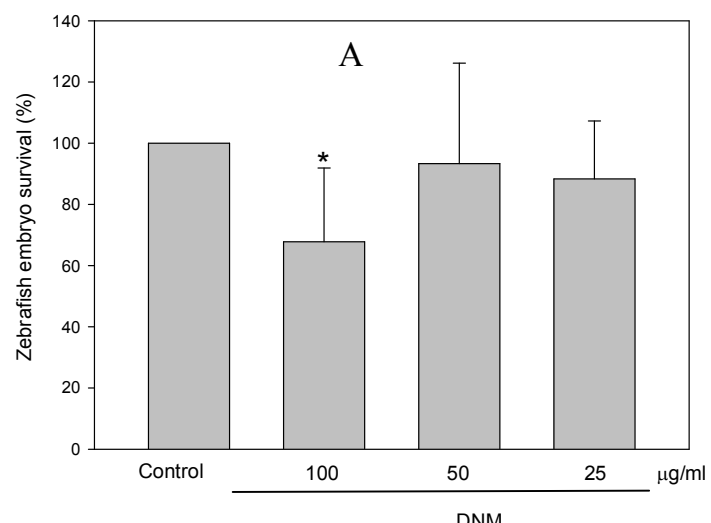

(B)
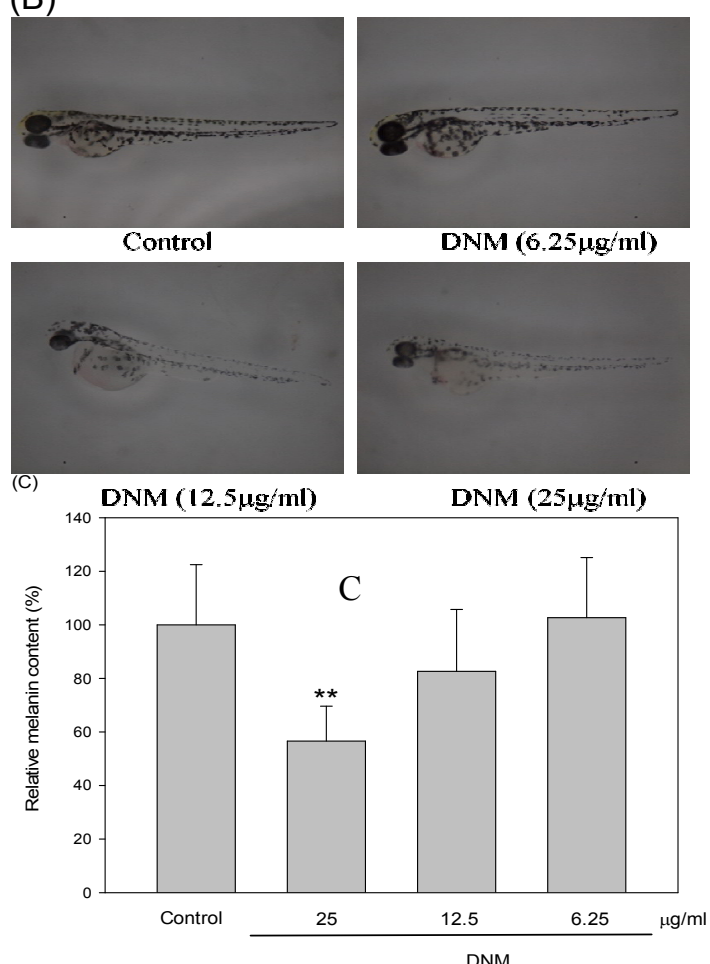

Figure 5: Melanogenesis inhibitory activity of DNM in zebrafish. (A) Melanin pigment was photographed (B) and its quantity was determined by a photometric method $(C)$. Data are mean $\pm S D(n=3)$; error bars denote standard deviation (SD); $p<0.05\left(^{*}\right)$; $p<$ $\left.0.001{ }^{* *}\right)$ relative to control

The biosynthetic pathway of melanogenesis and the key role of tyrosinase have been elucidated [1]. To study the effect of DNM on melanogenesis, we investigated the effect of DNM on intracellular tyrosinase activity in B16 cells. Surprisingly, DNM affected neither the enzyme activity (Figure 3A) nor the intracellular tyrosinase protein level (Figure 3B and 3C). Most melanogenesis inhibitors discovered thus far inhibit melanogenesis through down-regulation of intracellular tyrosinase activity [2]. However, our results suggest that DNM exhibited antimelanogenesis activity probably via a different mechanism. 
Antioxidants can interfere with oxidation processes by acting as free radical scavengers or ROS scavengers, and then down-regulate melanin production [12, 16-17]. For instance, vitamin $C$ or vitamin $E$ can reduce the photooxidation of preexisting melanin particles [18]. These vitamins with antioxidant activities are commonly applied in skin-lightening cosmetic formulations. Therefore, to explore the mechanism of the antimelanogenesis activity of DNM in B16 cells, the antioxidant capacity of DNM was investigated. The result of (DPPH and $\mathrm{ABTS}^{+}$scavenging activities) revealed that DNM possesses potent antioxidant activity. DNM also significantly reduced intracellular ROS in B16 cells treated for $2 \mathrm{~h}$ and $24 \mathrm{~h}$. Moreover, although vitamin $\mathrm{C}$ and Trolox have higher free radical scavenging activity than DNM in cell-free systems, DNM exhibited much higher intracellular ROS scavenging activity than the two vitamins. The results of the antioxidant experiments imply that DNM exhibits potent antimelanogenesis activity in B16 cells possibly through antioxidant activity.

Zebrafish is a well-known vertebrate model system in many research fields and has been established as a new in vivo model for evaluating the antimelanogenic activity of melanogenic regulatory compounds [14]. This animal model system has several advantages, including easy maintenance and handling of the animals and high efficiency of drug penetration through the skin. For these reasons, the zebrafish model was used as an in vivo system to evaluate the inhibition of melanogenesis by DNM. Our results showed that DNM significantly and dosedependently reduced the skin melanin content in the developed larvae.

\section{CONCLUSION}

The methanol fraction of $D$. nipponica ethanol extract inhibits melanogenesis in vitro in B16 melanoma cells as well as in vivo in zebrafish. Furthermore, the extract exhibits potent inhibition on melanogenesis that is not due to downregulation of intracellular tyrosinase activity, but probably as a result of its antioxidant activity in the cells. Based on the results of the study, the apparent antioxidant capacity of the extract from D. nipponica may find applications in cosmetic formulations of skin care products to prevent skin hyper-pigmentation. However, clinical studies need to be carried out for human applications.

\section{ACKNOWLEDGEMENT}

We thank $\mathrm{Dr}$ Tseng of the Department of Biological Sciences and Technology of the
National University of Tainan for his help in the animal experiments.

\section{REFERENCES}

1. Chang TS. An updated review on tyrosinase inhibitors. Int J Mol Sci 2009; 10: 2440-2475.

2. Chang TS. Natural Melanogenesis Inhibitors Acting Through the Down-Regulation of Tyrosinase Activity. Materials 2012; 5: 1661-1685.

3. Mapunya MB, Nikolova RV, Lall N. Melanogenesis and antityrosinase activity of selected south African plants. Evid Based Complement Altern Med 2012; 2012: 374017.

4. Yen FL, Wang MC, Liang CJ, Ko HH, Lee CW. Melanogenesis inhibitor(s) from Phyla nodiflora extract. Evid Based Complement Altern Med 2012; 2012: 867494.

5. Qing LS, Xue Y, Zheng Y, Xiong J, Liao X, Ding LS, Li BG, Liu YM. Ligand fishing from Dioscorea nipponica extract using human serum albumin functionalized magnetic nanoparticles. J Chromat A 2010; 1217: 4663-4668.

6. Kwon CS, Sohn HY, Kim SH, Kim JH, Son KH, Lee JS, Lim JK, Kim JS. Anti-obesity effects of Dioscorea nipponica Makino with lipase-inhibitory activity in rodents. Biosci Biotech Biochem 2003; 67: 14511456.

7. Luo D. Identification of structure and antioxidant activity of a fraction of polysaccharide purified from Dioscorea nipponica Makino. Carbohydrate Polymers 2008; 71: 544-549.

8. Liu JT, Chen $X Y$, Wang $Y Z$. Experimental study on antitumor effects of Dioscorea in vitro. Chinese $J$ Informat Trad Chinese Med 2004; 11: 15-21.

9. Ho ML, Hsieh YS, Chen JY, Chen KS, Chen JJ, Kuo WH, Lin SJ, Chen PN. Antimetastatic potentials of Dioscorea nipponica on melanoma in vitro and in vivo. Evid Based Complement Altern Med 2011; 2011: 507920.

10. Hsieh MJ, Yang SF, Hsieh YS, Chen TY, Chiou HL. Autophage inhibition enhances apoptosis induced by dioscin in Huh7 cells. Evid Based Complement Altern Med 2012; 2012: 134512.

11. Bradford MM (May 1976). A rapid and sensitive method for the quantitation of microgram quantities of protein utilizing the principle of protein-dye binding. Anal. Biochem. 1976; 72: 248-54.

12. Lin VC, Ding HY, Kuo SY, Chin LW, Wu JY, Chang TS. Evaluation of in Vitro and in Vivo Depigmenting Activity of Raspberry Ketone from Rheum officinale. Int J Mol Sci 2011; 12: 4819-4835.

13. Huang HC, Wang HF, Yih KH, Chang LZ, Chang TM. The dual antimelanogenic and antioxidant activities of the essential oil extracts from the leaves of Acorus macrospadiceus (Yamanoto) F.N. Wei et Y.K.Li. Evid Based Complement Altern Med 2012; 2012: 781280.

14. Choi TY, Kim JH, Ko DH, Kim CH, Hwang JS, Ahn S, Kim $S Y$, Kim CD, Lee JH, Yoon TJ. Zebrafish as a new model for phenotype-based screening of melanogenic regulatory compounds. Pigment Cell Res 2007; 20: 120-127.

15. Ding HY, Chang TS, Shen HC, Tai SSK. Murine Tyrosinase Inhibitors from Cynanchum bungei and Evaluation of in Vitro and in Vivo Depigmenting Activity. Exp Dermatol 2011; 20: 720-724.

16. Darr D, Fridovich I. Free radical in cutaneous biology. J Invest Dermatol 1994; 102: 671-675.

17. Yasui $H$, Sakurai $H$. Age-dependent generation of reactive oxygen species in the skin of live hairless rates exposed to UV light. Exp Dermatol 2003; 12: $655-661$. 
Ding et al

18. Ebanks JP, Wickett RR, Boissy RE. Mechanisms regulating skin pigmentation: the rise and fall of complexion coloration. Int J Mol Sci 2009; 10: 4066-4087. 